\title{
El cálculo de la Pascua y nuestros calendarios*
}

Satur y Alberto, dos de esos esforzados y sufridos labradores, siempre esperanzados de que con la nueva fase de la luna lleguen por fin las lluvias a esta tierra de Campos o Campos de tierra, habian oído decir que el Jueves Santo es el día de la luna llena. Apenas había concluido yo de explicarles que la luna llena puede caer en cualquier día de la Semana Santa, incluso el mismo día de Pascua, cuando llegó a mis manos el semanario de "Los Domingos de $A B C »$ (12.IV.981), donde el profesor Fernando Martín Asín intenta explicar "cómo se fija la fecha de la Semana Santa» y algunas cosas que considera él peculiares de este año de 1981. Francamente, no me ha convencido su argumentación que me parece, más bien, una mala interpretación o tergiversación de las normas del concilio de Nicea (325) sobre la celebración de la Pascua.

El cálculo de la fecha de la Pascua de Resurrección, fundamentalmente, se reduce a concordar fechas del calendario lunar judío con las nuestras del calendario solar: en concreto, el día 14 del primer mes del año religioso judío con una fecha de principio de primavera, que en nuestros calendarios puede caer entre el 21 de marzo y el 18 de abril.

Porque sabemos, en primer lugar, que la Pascua fue instituida y proclamada por Moisés, de parte de Dios, para que los israelitas la celebrasen el catorce del mes primero, por la tarde, la víspera de su salida de Egipto (Ex 12; Núm 28,16; Lev 23,5); y en segundo lugar, que ese mes primero del calendario judío, cuyo día 15 salieron de Egipto, era al principio de la primavera, como nos advierte un esclarecedor testimonio del Deuteronomio (16,2): "Guarda ef mes de Abib celebrando la Pascua de Yahvé, tu Dios, porque precisamente en el mes de Abib te sacó Yahvé, tu Dios, de Egipto, de noche».

En efecto, cuando los hebreros comienzan a sustituir el número ordinal de un mes por un nombre, al mes primero del año religioso le llamaron Abib,

\footnotetext{
* Escrita hace ya varios meses la presente glosa a lo decretado en el concilio de Nicea del año 325 sobre la celebración de la Pascua - mal interpretado, a mí entender, por algunos expositores - pienso que es llegado el tiempo oportuno para su publicación, al iniciarse este nuevo año de 1982 en el que se cumplirá el cuarto centenario de la reforma gregoriana del calendario y su inmediata aplicación en España.
} 
nombre tomado de los antiguos calendarios cananeos que significa «mes de las espigas"), cuando en Palestina blanquean ya las cebadas y los trigos comienzan a echar la espiga. Por eso, en la Vulgata, y antes algunos griegos, tradujeron $A b i b$ por «el mes de los nuevos frutos, que es al principio de la primavera». De aquí se desprende una norma fundamental para hallar la correspondencia de esa luna decimocuarta del primer mes - Abib o Nisán, como se llamó después - del calendario judío con un día determinado de nuestro calendario: Ese mes lunar, cuya luna $14^{a}$ no puede caer antes del equinoccio de primavera (21 de marzo), no podrá comenzar, por ende, antes del ocho de marzo, ni después del cinco de abril. Para averiguar, pues, a qué día de nuestros meses de marzo o abril corresponde esa luna $14^{\mathrm{a}}$, bastará sumar trece días al día del novilunio entre el ocho de marzo y el cinco de abril. Así, si la luna nueva es el día 8 de marzo, luna $14^{\text {a }}$ será el $21(8+13)$; si el 5 de abril ( 5 $+13=18$ ), luna $14^{a}$ será el 18 de abril. El 21 de marzo y el 18 de abril son, pues, las dos fechas tope entre las que puede caer la Pascua judía. Ni antes, ni después.

PERO PARA los CRISTIANOS lo más pronto que puede caer la Pascua de Resurrección es el 22 de marzo, y lo más tarde el 25 de abril. ¿Por qué esta diferencia? Vamos a intentar explicarlo, alegando ejemplos de años próximos o lejanos que ayuden a su mejor comprensión.

Sabido es que Jesucristo murió el día de la Pascua judía, 14 de Nisán, que aquel año era viernes - como consta en varias partes del cap. XIX del Evangelio de San Juan - y que resucitó el domingo, por la mañana. $Y$ es sabido igualmente que, para recordar la Resurrección, desde los primeros tiempos apostólicos los cristianos sustituyeron la celebración del sábado judío por la del domingo como día del Señor. Esta práctica fue unánime en toda la cristiandad. En lo que no hubo unanimidad fue en la fecha en la que debía celebrarse la Pascua cristiana: ¿el día de la luna decimocuarta, como los judíos o el domingo siguiente? La mayoría de las iglesias de la cristiandad había optado también por el domingo. Pero las iglesias de la provincia eclesiástica del Asia Menor la celebraban el día catorce de la luna del primer mes.

«Porque las iglesias de toda Asia - dice Eusebio HE. V, 23,1- apoyándose en una tradición muy antigua, pensaban que era preciso guardar el decimocuarto día de la luna para la fiesta de la Pascua del Salvador, día en que se mandaba a los judios sacrificar el cordero y en que, cayera en el día que cayera de la semana, era necesario a toda costa poner fin a los ayunos; mientras que las iglesias del resto del mundo guardaban el ayuno hasta el dia de la Resurrección».

Y en la fuerte controversia que mantuvieron las iglesias del Asia con la de Roma en la última década del siglo II, cuando varios sínodos y reuniones de obispos decretaron que el misterio de la resurrección se celebrase solamente en domingo, los de Asia replicaban que era también tradición apostólica la costumbre suya de celebrar "como día de Pascua el de la luna decimocuarta» (lbidem, cap. 24,6). 
LAS NORMAS DE NICEA (325)

A semejante controversia y, sobre todo, a la disparidad disciplinar que ella entrañaba procuró poner fin el concilio celebrado en Nicea el año 325, decretando para ello: $10^{\circ}$ Que la Pascua se celebrase e/ domingo siguiente a la luna decimocuarta del mes primero; 2. $^{\circ}$ Que el equinoccio de primavera es el día 21 de marzo; y $3 .^{\circ}$ Que si el día de la luna decimocuarta es domingo, la Pascua se celebrará el domingo siguiente "para no coincidir con los judíos».

El primer mes del año religioso hebreo - ya queda indicado arriba - es el mes cuya luna $14^{\mathrm{a}}$ cae el 21 de marzo o después de esta fecha. $Y$ a esta fecha "convencional» del 21 de marzo como equinoccio de la primavera hemos de atenernos, a tenor de la segunda norma de Nicea, aunque el equinoccio astronómico y real pueda tener lugar también el 20 o hasta el 19 de marzo. El 21 de marzo fue la fecha en que tuvo lugar el equinoccio el año 325 , el del concilio de Nicea.

\section{LOS CALENDARIOS JULIANO Y GREGORIANO}

El emperador Julio César mandó reformar el calendario (47 a.C.) para restablecer el equinoccio de primavera en el día 25 de marzo, como en tiempos de Numa. Según este calendario, el año solar tenía 365 días y seis horas de duración. Esas seis horas, cada cuatro años, formaban un día más: los años bisiestos. Pero había un error en este cálculo: faltaban 11 minutos y 14 segundos para las seis horas. Debido a la acumulación de este erroranual, cuando se celebró el concilio de Nicea, ocurrió el equinoccio de primavera el día que el calendario señalaba como 21 de marzo, el vez de 25; y en 1582 cuando el calendario señalaba como 11 de marzo, en vez del 21 que era la fecha fijada en Nicea.

Para corregir esta irregularidad, el papa Gregorio XIII mandó suprimir esos diez días erroneamente acumulados desde el concilio de Nicea y restablecer así el 21 de marzo como fecha del equinoccio de primavera. Los días suprimidos fueron los que median entre el 4 y el 15 de octubre del año 1582: del 4 se pasó al 15 (no al 5). Para no recaer en el error del calendario juliano, a partir del año 1600 sólo serán bisiestos los años centenarios divisibles por 400 (2.000 ó 2.400, por ejemplo; pero no lo han sido ni 1700 ni 1800 ni 1900) '.

1. Por eso, Sta. Teresa, que murió al anochecer del 4 de octubre, no se enterró hasta el 15. En esto consiste esencialmente la reforma gregoriana del calendario. Reforma que no ha sido aceptada todavía por la Iglesia Ortodoxa, lo que nos explica por qué no coincide exactamente la celebración de la Pascua entre cristianos orientales y occidentales. Ellos continúan usando el calendario juliano.

Tampoco el nuevo calendario mandado establecer por el Papa de acuerdo con las teorías del sabio matemático napolitano, Luis Lilio, fue aceptado inmediatamente en las naciones protestantes. En Inglaterra, por ejemplo, no fue admitido hasta 1752, año en que se introdujo el New Style Kanlendar, por lo que todas las fechas entre 1582 y 1752 , en Inglaterra, se refieren forzosamente 
Regla para CALCULAR El diA de LA Pascua

Dicho esto, la regla para calcular el día de Pascua de un año cualquiera puede formularse así: Hállese por medio de las tablas de epactas (o por el calendario) el novilunio después del 7 de marzo; añádanse trece días y tendremos el día $14^{\circ}$ de la luna del primer mes de los judios. La Pascua será el domingo siguiente a ese día $14^{\circ}$ de la luna. Algunos ejemplos históricos nos ayudarán a comprender mejor la aplicación de esta regla y su validez.

¿Qué día tuvo lugar la Pascua, por ejemplo, el año 1598? En la tabla de epactas veo que al año 1598 corresponde el $n .{ }^{\circ} 23$ de epacta (dias que tenía la luna al comenzar el año). Por consiguiente los novilunios serán: 8 de enero, 6 de febrero, y 8 de marzo. Luna $14^{\mathrm{a}}$ será $(8+13)$ el 21 de marzo. Estamos en el primer mes. Como el 21 era sábado, la Pascua fue el día siguiente, 22 y domingo. Un año típico de lo más pronto que puede caer la Pascua para judíos y cristianos. Para los judíos podrá repetirse siempre que el novilunio sea el 8 de marzo. Pero la coincidencia de que el día 22 sea luna $15^{\mathrm{a}}$ y domingo es mucho más rara. Desde la reforma gregoriana del calendario (1582) sólo sé que se haya dado cuatro años en 1598, 1693, 1761 y 1818. Y no volverá a suceder antes del siglo XXIII de la Era cristiana.

Avancemos un paso más. Supongamos que, habiendo sido el novilunio el 8 de marzo, el 21 fuese domingo - como sucedió los años 1655, 1723, y 1875-. Pues bien, esos años, «para no coincidir con los judios», la Pascua se celebró el domingo siguiente, 28 de marzo. El caso de retrasar toda una semana la celebración de la Pascua «para no coincidir con los judíos», se dará siempre que la luna $14^{\mathrm{a}}$ pascual sea domingo. Reciente está todavía el caso del año 1970, en el que «para no coincidir...» el día 22 de marzo, celebramos la Pascua el 29; y más reciente aún el de 1977 en el que, por la misma razón, se trasladó del 3 al 10 de abril.

Pero el más significativo de estos traslados, el que nos explica al mismo tiempo por qué lo más tarde que puede caer la Pascua es el 25 de abril, tuvo lugar el año 1943. Ese año el novilunio fue el 5 de abril -como este año de 1981 según el cómputo eclesiástico-; día $14^{\circ}$ de la luna fue el 18, domingo; para no coincidir... etc.», la Pascua se celebró el 25 de abril. En cambio, este año de 1981, habiendo sido también el novilunio el 5 de abril por tener el mismo número 24 de epacta que el 1943, la Pascua se celebró seis días antes, el 19 de abril, porque la luna $14^{\mathrm{a}}$ había sido el día anterior, sábado.

al calendario juliano. Y que es erróneo repetir típicamente, como estamos constantando lo hacen en España los diversos sectores de la radio y de la prensa: que Cervantes y Sakespeare murieron en el mismo dia del 23 de abril 1616. Ya que, en 1616, cuando en España era 23 de abril en Inglaterra era todavía 13 de abril. 
LO PECULIAR DEL ANO 1981

La exactitud de los ejemplos aducidos para la celebración de la Pascua en distintos años la puede comprobar el lector consultando cualquier tabla pascual, desde la reforma gregoriana hasta el año 2.000. Sin embargo, con el calendario de pared a la vista, cualquiera de mis lectores podrá objetar: el novilunio de abril de este año de 1981 no fue el día 5, como Vd. dice, sino el 4. Así es, en efecto. Añadiré más todavía: ni el de abril ni ninguno de los trece novilunios (este año de 1981 es año embolismal, de trece lunaciones) coincide con los correspondientes a la epacta 24 del calendario eclesiástico. Todos van una fecha adelantados. Por eso lo que interesa subrayar de cuanto se lleva dicho es que, para el cálculo de la Pascua, hemos de atenernos a las normas del concilio de Nicea y a las reglas del calendario gregoriano, aun cuando, como este año de 1981, las fechas del equinoccio y de los novilunios del calendario eclesiástico no se correspondan más que aproximadamente con los datos reales astronómicos. Así, el equinoccio de primavera tampoco fue el 21 de marzo, sino el 20 , a las 17 horas $y$ tres minutos. $Y$ el plenilunio astronómico habia tenido lugar dos horas antes: a las $15 \mathrm{~h} .13 \mathrm{~m}$. y $12 \mathrm{~s}$. exactamente. Pero ni en las normas ni en las reglas se menciona para nada el plenilunio.

Con todo, tanto partiendo de los novilunios del calendario eclesiástico (7 de marzo y 5 de abril) como de los del calendario astronómico (6 y 4), la Pascua tenía que celebrarse el 19 de abril. No podía ser en marzo, porque en ambos casos la luna tenía ya más de catorce días el día del equinoccio. Tenía que ser, pues, en la lunación de abril y el domingo, día 19, porque, en ambos casos, ése es el domingo siguiente a la luna $14^{a}$.

Por no haber tenido en cuenta estas consideraciones, el profesor Martín Asín en su artículo mencionado, hace el cálculo a base de los datos astronómicos sobre el equinoccio y los novilunios, llegando a conclusiones que no pueden ser aceptadas como interpretación correcta de lo decretado en Nicea, sino como una interpretación coja o, hasta me atrevería a decirlo, una tergiversación. Como tales han de valorarse los asertos de que la Pascua podría haberse celebrado este año en marzo, de haber tenido lugar dos horas después el plenilunio; $y$, con mayor razón, la de que «resulta claramente que dicha Pascua de Resurrección tendría que haber sido el domingo 26, porque, efectivamente, también el día 19 es domingo». ¿No hemos demostrado que la fecha tope, la más tardía de la Pascua, no puede pasar del 25 de abril? ¿No lo confirman además las tablas pascuales? $Y$, ante el hecho de que la fecha fijada ha sido el 19 de abril, se pregunta todavía el profesor, insistiendo en lo del plenilunio en lugar de la luna $14^{\mathrm{a}}$ : «Entonces, ¿debemos pensar que cuando la luna llena siguiente al equinoccio caiga en domingo es ese día la Pascua o debemos saltar al siguiente? Ahi queda el punto dudoso».

Por supuesto que ni debemos saltar al domingo siguiente, ni el punto es dudoso. Sencillamente, que el día de referencia señalado en Nicea para saber qué domingo debemos celebrar la Pascua no fue el día de la luna llena, sino el día 14 de dicha lunación, el día de la Pascua judía; «el domingo siguiente a la luna decimocuarta del mes primero». No simplifiquemos tanto lo decretado 
en Nicea diciendo que la Pascua debe celebrarse el domingo siguiente a la primera luna llena que sigue al equinoccio de primavera, porque semejante simplificación, además de enrevesada, es falsa, y complica el cálculo de la Pascua y se presta a malas interpretaciones. Es falsa porque se basaria en la falsa suposición de que el plenilunio es a los 14 días de la luna, cuando la luna sólo está en oposición el día 16, como nos confirman los datos astronómicos para esta lunación de abril: novilunio día 4, plenilunio día 19. Que se presta a malas interpretaciones, ahí está el artículo del profesor Martín para probarlo. Olvidémonos, pues, del plenilunio para no complicar más todavía el cálculo del día de la Pascua. 